\title{
Student Perceptions Of The Value Of A University Laptop Program
}

\author{
Claudia Orr, Northern Michigan University \\ Bruce Sherony, Northern Michigan University \\ Carol Steinhaus, Northern Michigan University
}

\begin{abstract}
In the fall of 2000, when a mandatory laptop program was initiated at a Midwest regional university, a faculty research team began a longitudinal study to determine student perceptions of the value of the program. Value was defined as usefulness of the computer, reasonable price for the computer and the quality of the computer. A survey of 1,000 first-time full time university students were surveyed in 2000 and five years later in the fall of 2005. Significant differences were found on all three variables indicating that student perceptions of the usefulness, price, and quality of the computer increased from 2000 to 2005. Based on these findings, recommendations are offered to administrators and faculty who may be considering the adoption of a computer requirement.
\end{abstract}

Keywords: laptop computers, university, student perceptions, computer ownership

\section{INTRODUCTION}

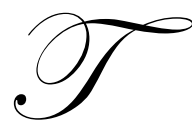

he 2005 fall semester at Northern Michigan University, a public university of 9,000 students, marked the fifth anniversary of their Teaching, Learning and Communication (TLC) initiative. The TLC is a comprehensive, cross-curriculum program that puts a laptop computer in the hands of every full-time student. Their vision for education in the $21^{\text {st }}$ century is a learning environment that embraces technology to enhance student access, promote the development of independent learners and encourage greater student-faculty communication and collaboration. Northern has been cited nationally and internationally as a result of the TLC initiative. In 2001, the university was ranked $24^{\text {th }}$ in Yahoo! Internet Life's " 100 Most Wired Colleges." The university was recognized as a "Laureate" award recipient in Computer World's Honors Program in 2003, a distinction selected by CEOs of the world's leading technology companies. Intel Corporation then ranked Northern $19^{\text {th }}$ among the top 50 "Most Unwired" campuses for 2005.

The TLC program was fully implemented and the first distribution held in 2000 after two pilot years. All full-time graduate and undergraduate students (registered for 12 or more credit hours) are required to lease a laptop through the university. Continuing students who pre-register for the following fall are able to use the computer through the summer at no additional charge. The computer comes with a standard set of applications including 24hour access to the campus network and the Internet. The university issues the laptops to students on a two-year replacement cycle. When the program was implemented in 2000, all students were required to lease the same laptop. Two years later, however, art and design majors were required to lease a different model. Walk-in, telephone, and email Help Desk support for hardware and software issues is also available.

Planning, coordinating, and communicating are key components of a successful laptop implementation; marketing the program to incoming students is especially important (Carnevale and Young, 2006). It is imperative that faculty, parents and students find value in the program. Therefore, when the laptop program began at Northern Michigan University in the fall of 2000, a faculty research team initiated a longitudinal study to assess student perceptions of the value of the program. In this study, value was defined in terms of usefulness of the computer, the 
value acquired for the cost of the computer, and the quality of the computer. The researchers believe the results of this study will be useful to administrators and faculty considering a computer requirement.

\section{REVIEW OF LITERATURE}

The first colleges to require computers were the military academies, which started putting a desktop in every cadet's room in 1983 (Wilgoren, 2000). Drew University in Madison, New Jersey, was the pioneer for laptop universities in the United States when they began providing laptops to all incoming students in 1988 (Kuo, 1995). During the next decade, owning or leasing a computer gradually became a requirement for students attending both public and private universities throughout the country. Today, more than 150 colleges require students to lease or purchase computers with a few more colleges adopting laptop programs each year (Carnevale and Young, 2006).

Universities attempt to fulfill several goals with the adoption of a laptop program. Building and maintaining student competencies in information technology is of highest priority. Another primary goal is freeing up resources from the use of costly computer labs that constantly need high maintenance and new hardware and software (Newby, 2003). For some schools, the programs can be a plus in marketing as well, helping to project the image that the campuses are state of the art (Carnevale and Young, 2006) and produce more technologically skilled graduates. In public universities where the student body has a wide range of abilities and experiences, a computer requirement offers equal access to technology for all students.

As laptop programs became more prevalent in educational institutions, reports of their effectiveness began appearing in the literature. In fact, Tiu, Guglielmi and Walton (2002) emphasize, "as more and more higher education institutions invest heavily in technology, it is crucial that institutions conduct ongoing assessment to determine the return on their investments - effectiveness in teaching and an increase in student learning." Li and Newby (2002) report that the literature on laptop programs in education focuses on three general areas: (1) administrative reports and reviews on the rationale, planning and implementation of the laptop requirement; (2) how portable computers can be incorporated into teaching and the teaching, learning and cultural changes that result; and (3) issues or concerns that emerged during the implementation process of laptop programs. Olsen (2001) explains, however, that research into the educational use of laptops has only recently begun and Li and Newby (2002) say that the long-term impact of laptop programs on education remains to be seen.

According to Li and Newby (2002), an assumption shared by the literature on laptop programs is that students involved are treated as passive recipients, waiting to be affected by the introduction of laptops in their lives. Distinctions among students have not been particularly considered concerning their perceptions towards laptops and laptop programs. In fact, Orlikowski and Gash (1994) explain that to interact with technology, people have to make sense of it; they develop assumptions, expectations, and knowledge of the technology which shapes their actions toward it. These interpretations are significant in influencing how people think about and act toward technology and should be considered in studying the implementation of technological change. Therefore, in analyzing the implementation of laptop programs in education, it is critical to examine student perceptions at various stages in the program.

Most research on student perceptions of laptop programs have been with students who are already participants in the program. Randall (2001) reports that students at some universities that require computer ownership have been disappointed. To most students, a computer requirement meant that computers would be used in almost all classes. However, few classes were computer intensive. As Olsen (2001) explains, restructuring courses takes commitment and time for faculty members to create course content that is electronic. This is supported by McVay, Snyder and Graetz (2005). They found that the value of a laptop program for students depends primarily on their perception that the laptops are being used for academic purposes. Simply requiring students to lease laptops without smoothing the way for faculty members to integrate the technology into their courses is a recipe for disaster. $\mathrm{Li}$ and Newby (2002) concur. After examining a laptop implementation to understand student roles and reactions and the match between real and perceived benefits of graduate students, they report that students perceived the laptops as being underutilized in the classroom and their uses did not justify the expense. 
At Wake Forest University, a leader in laptop campuses, students protested the program when it was proposed in 1994 because of the resulting tuition increase (Young, 1997). However, little research has been reported on student perceptions of a laptop program for students entering the institution for the first time. In this paper, we will compare student perceptions of the laptop program for first-time students during the fall of 2000 when the laptop program was initially implemented with the perceptions of first-time students five years later. Results may be helpful to universities who are in the initial stages of implementing a laptop program.

\section{RESEARCH DESIGN}

A longitudinal study commenced in the fall of 2000 to examine student perceptions of the value of a mandatory laptop program at a public university in the Midwest. A random sample of 1,000 first-time students was sent a paper survey with a self-addressed stamped return envelope. Five years later, in the fall of 2005, a random sample of 1,000 first-time students was sent an e-mail requesting they complete an on-line survey. Identical questions to the 2000 survey were included in the on-line document.

Participants were asked how confident they were that the laptop program provided a useful educational tool, a reasonably priced tool, and a quality computer. Seven point scales were utilized to measure the respondent's level of confidence as a useful educational tool, a reasonably priced tool and a quality tool. The response range was anchored from (1) Not at all Confident to (7) Highly Confident.

\section{HYPOTHESES}

The following research hypotheses were investigated:

H1. The perceptions that the laptop program provides a useful educational tool for first-time students will increase from 2000 to 2005 .

H2. The perceptions that the laptop program provides a reasonably priced tool for first-time students will increase from 2000 to 2005.

H3. The perceptions that the laptop program provides a quality computer for first-time students will increase from 2000 to 2005 .

\section{METHODOLOGY}

Participants. In the fall of 2000, a random sample of 1,000 surveys was mailed to first-time, full-time new students at a Midwest regional university. Given a total population $(\mathrm{N}=1,259)$, the mailing achieved a $32.4 \%$ response rate, yielding $(\mathrm{n}=324)$ usable responses.

In the fall of 2005, a web survey was used as a replacement for the conventional mailed questionnaire used in 2000. A random sample of 1,000 first-time, full-time new students at the same Midwest regional university were asked via e-mail to complete a web survey. Given a total population of first-time, full-time new students $(\mathrm{N}=1,372)$, the web survey achieved a $42.4 \%$ response rate, yielding $(n=424)$ usable responses. No further sampling was undertaken.

Analysis. The initial data for both surveys was transferred from questionnaire format and recorded into Excel files. The data was then transferred into SPSS. Kolmogorov-Smirnov test statistics were employed to determine if the two datasets differ significantly. The K-S test was chosen because of the independence of the two samples and because it has the advantage of making no assumption about the distributions of each sample.

\section{RESULTS}

\section{Useful Educational Tool}

Respondents were asked to rate the usefulness of the laptop program as an educational tool during the fall of 2000 and again during the fall of 2005. Table 1 presents the ratings for the two samples over the five-year 
interval. During 2000, $13.6 \%$ of the respondents were "not at all confident" and $25.6 \%$ reported that they were "highly confident" that the laptop program provides a useful educational tool. During 2005 , only $1.4 \%$ of respondents were "not at all confident" and $61.1 \%$ were "highly confident" that the laptop program provides a useful educational tool.

Table 1

\begin{tabular}{lccccccrrr}
\hline & \multicolumn{1}{c}{ Laptop Program Provides a Useful Educational Tool } & & \\
\hline & $\begin{array}{c}\text { Not at all } \\
\text { Confident }\end{array}$ & $\mathbf{2}$ & $\mathbf{3}$ & $\mathbf{4}$ & $\mathbf{5}$ & $\mathbf{6}$ & $\begin{array}{c}\text { Highly } \\
\text { Confident }\end{array}$ & Total \\
\hline Fall 2000 & 43 & 8 & 17 & 41 & 57 & 70 & 81 & 317 \\
Fall 2005 & 6 & 6 & 9 & 26 & 49 & 74 & 267 & 437 \\
\hline Total & 49 & 14 & 26 & 67 & 106 & 144 & 348 & 754
\end{tabular}

Chart 1 presents a bar chart for the 2000 and 2005 samples. A close comparison of both distributions shows that significant differences exist between the two time periods, lending support for Hypothesis 1 (K-S Z=4.818, $\mathrm{p}<.001)$.

\section{Chart 1}

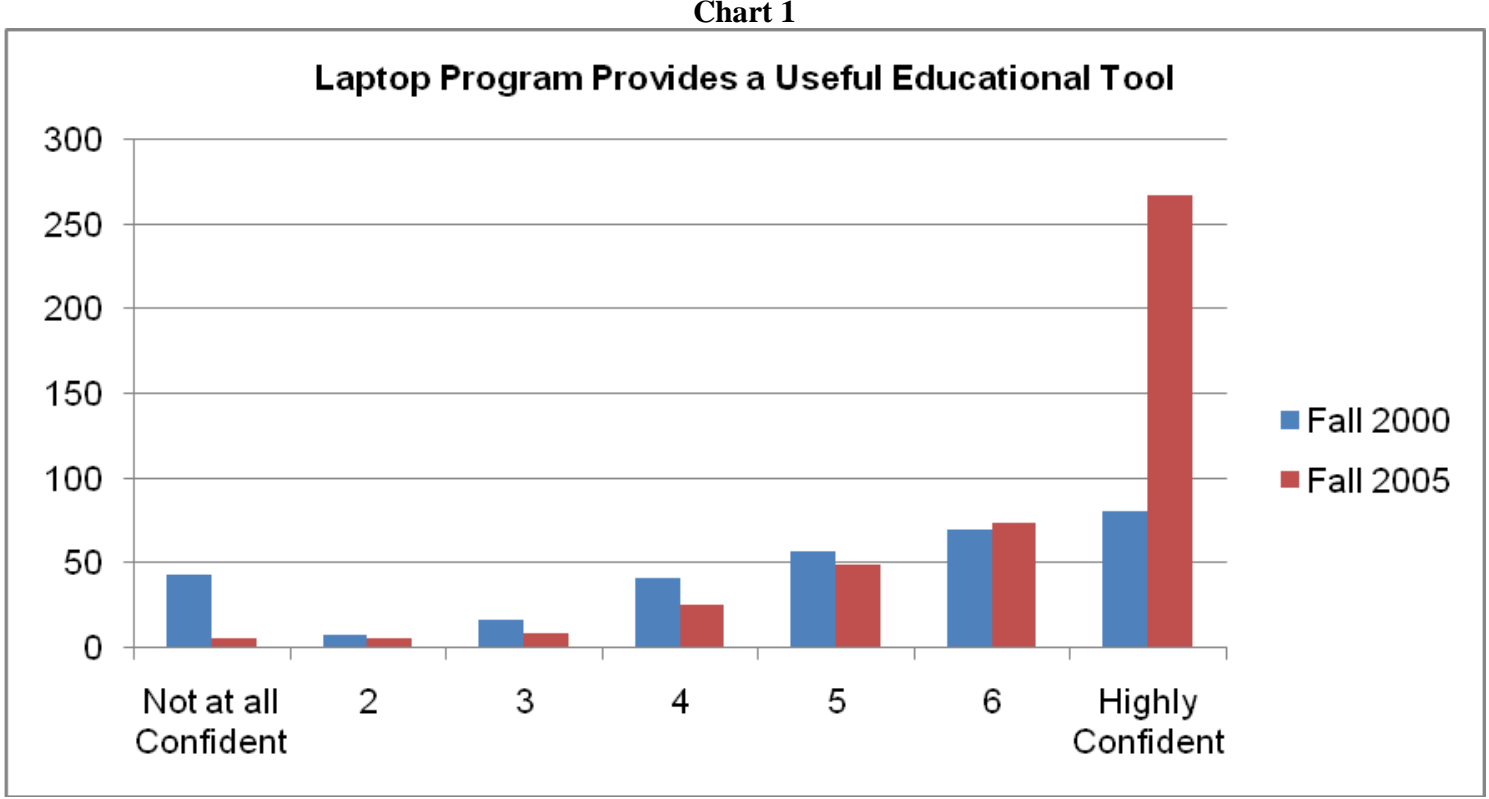

\section{$\underline{\text { Reasonably Priced Educational Tool }}$}

The price of the computer was the second measure of value that was used to determine the value of the program. In this regard, respondents were asked to rate the reasonableness of the price that they had to pay to lease the computer. During the fall of $2000,21.1 \%$ of the respondents were "not at all confident" and $11.3 \%$ of respondents were "highly confident" that the program provides a reasonably priced computer. During the fall of 2005 , only $3.1 \%$ of respondents were "not at all confident" and $46.6 \%$ of respondents were "highly confident" that the program provided a reasonably priced computer. Table 2 presents the response distributions for the two time periods. 
Table 2

Laptop Program Provides a Reasonably Price Tool

\begin{tabular}{lcccccrrr}
\hline & $\begin{array}{c}\text { Not at all } \\
\text { Confident }\end{array}$ & $\mathbf{2}$ & $\mathbf{3}$ & $\mathbf{4}$ & $\mathbf{5}$ & $\mathbf{6}$ & $\begin{array}{c}\text { Highly } \\
\text { Confident }\end{array}$ & Total \\
\hline Fall 2000 & 67 & 27 & 35 & 42 & 59 & 52 & 36 & 318 \\
Fall 2005 & 13 & 8 & 16 & 47 & 60 & 82 & 197 & 423 \\
\hline Total & 80 & 35 & 51 & 89 & 119 & 134 & 233 & 741
\end{tabular}

A bar chart of the respondents' responses to the question regarding the laptop as a reasonably priced tool, for the two time periods is shown in Chart 2. The perception of increasing confidence in price reasonableness becomes very evident in the 2005 sample. A comparison of the 2000 sample with the 2005 sample shows significant differences in the responses, indicating support for Hypothesis 2 (K-S Z=5.158, p<.001).

\section{Chart 2}

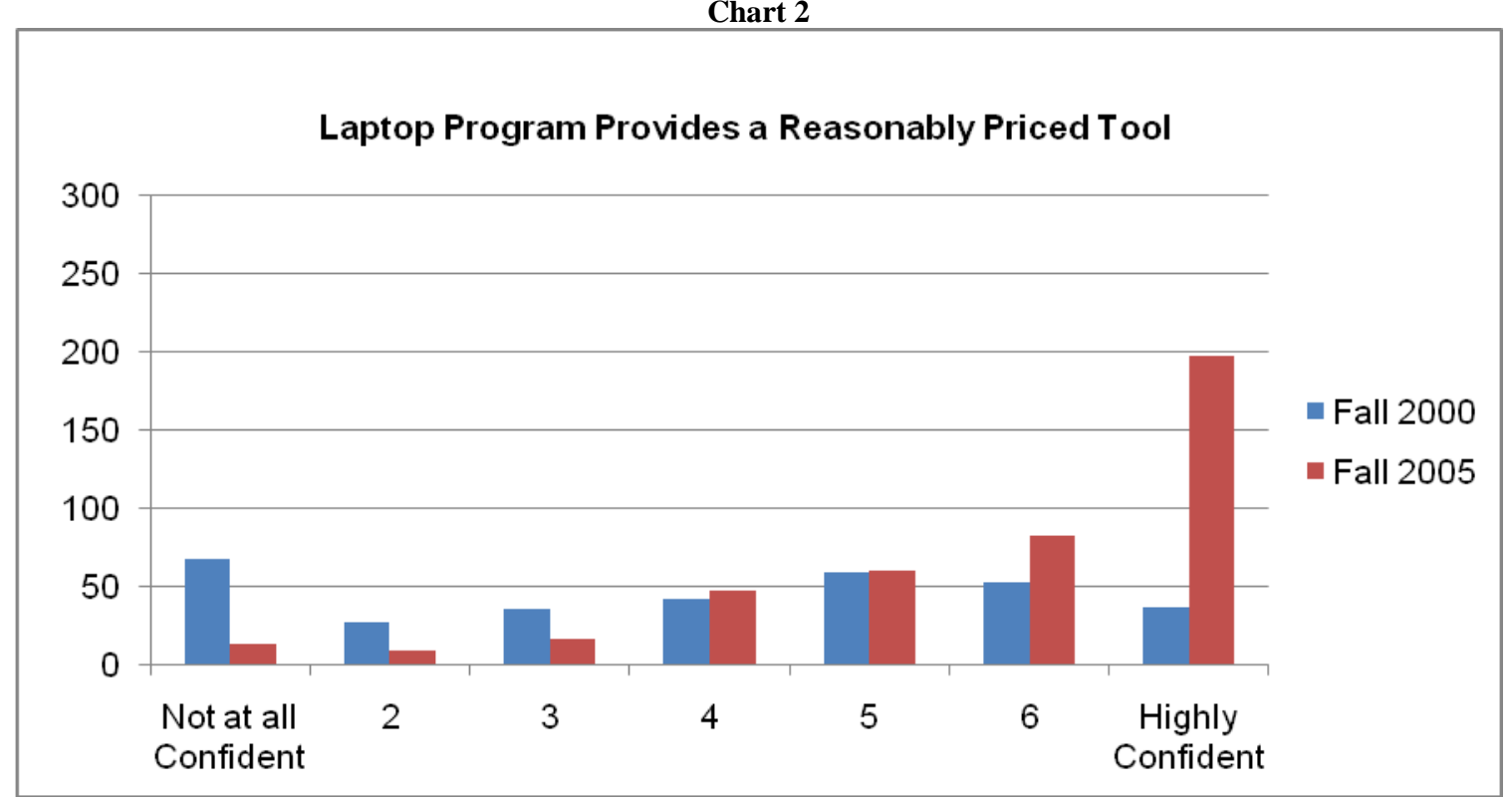

\section{Quality Computer}

The quality of the computer was the third measure of value of the program. Respondents were asked to rate the quality of the computer that they received in the laptop program. During the fall of $2000,7.7 \%$ of the respondents were "not at all confident" and $17.3 \%$ of respondents were "highly confident" that the program provided a quality computer. During the fall of 2005 , only $2.5 \%$ of respondents were "not at all confident" and $35.2 \%$ of respondents were "highly confident" that the program provided a quality computer. Table 3 presents the response distributions for the two time periods. 
Table 3

Laptop Program Provides a Quality Computer

\begin{tabular}{lcccccrrr}
\hline & $\begin{array}{l}\text { Not at all } \\
\text { Confident }\end{array}$ & $\mathbf{2}$ & $\mathbf{3}$ & $\mathbf{4}$ & $\mathbf{5}$ & $\mathbf{6}$ & $\begin{array}{r}\text { Highly } \\
\text { Confident }\end{array}$ & Total \\
\hline Fall 2000 & 25 & 21 & 31 & 39 & 62 & 90 & 56 & 324 \\
Fall 2005 & 11 & 15 & 21 & 59 & 68 & 108 & 153 & 435 \\
\hline Total & 36 & 36 & 52 & 98 & 130 & 198 & 209 & 759
\end{tabular}

Chart 3 shows a bar chart of the respondents' reactions to a quality computer for the two time periods. The perception of increasing confidence in the quality of the computer becomes very evident in the 2005 sample. A comparison of the 2000 sample with the 2005 sample shows significant differences in the responses, indicating support for Hypothesis 3 ( $\mathrm{K}-\mathrm{S} \mathrm{Z}=2.438, \mathrm{p}<.001)$.

Chart 3

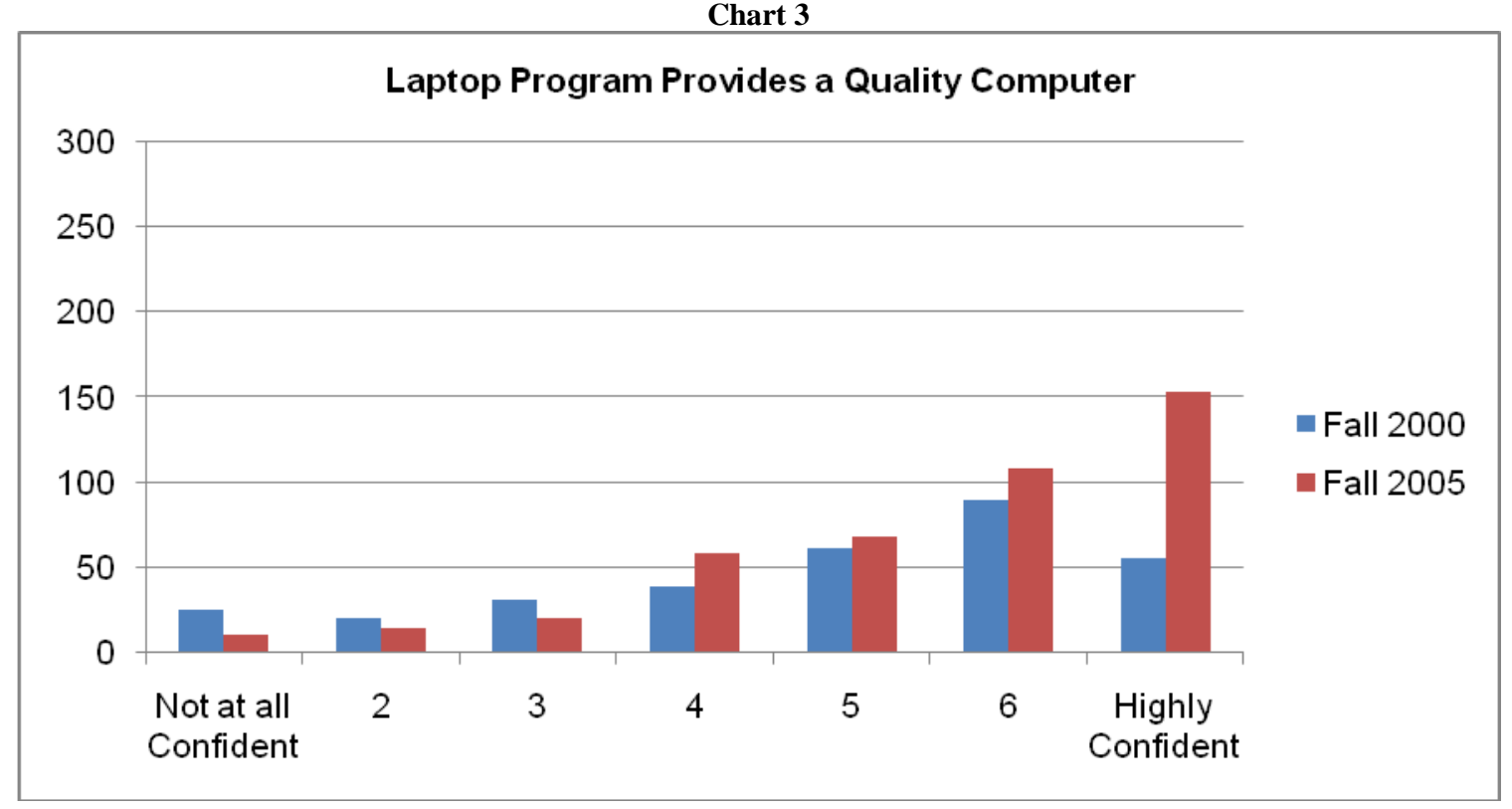

\section{LIMITATIONS}

Several limitations to this study should be reported. There is a change in survey methods from a mail survey in 2000 to a web-based survey in 2005 . There is a possibility that the characteristics of the two samples were different because of the change in survey methodology. Second, the university made a billing change for the school year of 2002-2003 which might have affected students' opinions of the economic value of the program. In 2000, the fee for the laptop program was listed on student bills as a separate fee. Therefore, it was very visible. By the academic year of 2002-2003, the laptop fee was blended into tuition which allowed student loan and aid programs to pay for computer charges as part of tuition. Therefore, the cost to an individual student of participating in the laptop program was not nearly as apparent in 2005 as it was in 2000.

\section{DISCUSSION}

A comparison of the three tables and bar charts of the research findings shows that the overall level of student perceptions on the value of the laptop program for the explanatory variables has increased from 2000 to 2005. This is further confirmed by the significant differences found in the Kolmogorov-Smirnov test statistics. 
Over the five year interval, student value of the program may be increasing for a number of reasons. The increase in usefulness is most likely due to several causes. In the laptop program, students are issued a new computer every other year. Newer models of computers have more memory, more speed and offer improvements over earlier models. During this period, students were most likely using computers more during their secondary education and therefore have an increased level of confidence in using technology. Computers also became a normal tool for students to function effectively and to be productive in their personal lives; therefore, they come to college with the expectation of anytime, anywhere computer access.

During the five year interval, the cost of the computer for students remained about the same. The increasing confidence in the price reasonableness of the computer may be explained by a number of factors. In 2000, the laptop was a separate fee on tuition bills. By 2005, however, this fee was blended into tuition and not as readily apparent. This may have affected perceptions of the price of the computer. The positive reputation of the program that evolved during this time probably helped to improve the perception of the reasonableness of the price of the computer. The laptop program was recognized regionally, nationally, and internationally and the program's reputation itself may transpire into a higher level of value. Replacing computers every two years, updating software in between replacement cycles, and implementing wireless access throughout the university may also have helped to create a positive perception of the cost reasonableness. In addition, with students using computers more in their personal lives, a more positive attitude toward the price may have developed. Finally, during this time period, more and more institutions of higher learning implemented computer requirements. This trend resulted in an acceptance of the computer as a normal expense for college.

The perceived quality of the computer program significantly increased from 2000 to 2005 . Quality characteristics may be explained again by the investment in up-to-date hardware and software, a well staffed help desk to aid students with problems using the computers, and an effective repair department with adequate inventories of computer parts.

\section{CONCLUSIONS AND RECOMMENDATIONS}

The value of a laptop program was measured at a Midwestern university. Value was measured by students' perceptions of the following three variables:

1. The laptop program provides a useful educational tool.

2. The laptop program provides a reasonably priced educational tool.

3. The laptop program provides a quality computer.

To examine the value of a laptop program, sample investigations were conducted in 2000 and 2005 . The perceived level of the value of the program increased from 2000 to 2005. An attempt was made to explain the reasons for the increase in the perceived level of usefulness, price reasonableness and quality of the computer. The following recommendations are made based on an evaluation of these value characteristics and the researchers' experiences with this laptop program.

Useful Educational Tool. The five year experience with the laptop program showed an increase in the usefulness of the technology. One issue became the need for multiple platform computers. Some disciplines such as art and design utilize software for a different computer platform. At Northern Michigan University, a second computer platform was adopted in 2002-2003 in response to the needs of specific disciplines.

It is recommended that the administration and faculty develop a unified purpose for a laptop program as well as a set of goals for the program to achieve. Faculty members have to be convinced that the program will be useful and should find ways to integrate the technology into the classroom. Faculty must maintain an interest in the program and assess the program's ability to achieve its goals and objectives. A dialogue between the faculty and administration should be ongoing to agree on the degree of goal achievement of the program and to carefully evaluate recommended changes to be implemented in the future. The perceived level of usefulness of a laptop program will be associated with the careful management and monitoring of the program. 
Reasonably Priced Educational Tool. From 2000 to 2005, students' perceptions of the economic benefits of the program increased. Students have to become convinced that the program is worthwhile enough to improve their future by further developing their skills and potential earning power. The faculty should be surveying alumni to determine how well the laptop program prepared them for their careers and the limitations if the program had not existed.

Quality Computer. Perceptions of the quality of the computer increased from 2000 to 2005. Computer quality is an important trait for the reputation of the university. The faculty and administration must develop a proper foundation and infrastructure to maintain and continually improve the quality of the program. Quality characteristics include the quality of the hardware and software, competent technical personnel, and availability of onsite repair facilities. The efficient allocation and distribution of computers to students also reflect the program's quality. Laptop programs are expensive. The administration must be serious about adequately investing capital into the program and in supporting and improving the program once it's implemented. A quality improvement program and training programs for faculty and administrators are also important quality considerations.

\section{REFERENCES}

1. Carnevale, D. and Young, J. (2006). The challenges and benefits of requiring students to buy laptops. (Excerpt). The Chronicle of Higher Education, 52(38), A39. Retrieved November 17, 2006, from InfoTrac OneFile database.

2. Kuo, C. (2005). Wireless technology in higher education: The perceptions of faculty and students concerning the use of wireless laptops (Doctoral dissertation, Ohio University, 2005). Retrieved November 12, 2006, from http://rave.ohiolink.edu/etdc/view?acc_num=ohiou1125521504.

3. Li, B. and Newby, G.B. (2002). Laptop requirement usage and impact in graduate ILS education. Proceedings of the American Society for Information Science and Technology Annual Meeting, Philadelphia, PA, November 18-21, 83-91.

4. McVay, G., Snyder, K. and Graetz, K. (2005). Evolution of a laptop university: A case study. British Journal of Educational Technology, 36(3), 513-524.

5. Newby, G. (2003). Student laptop ownership requirement and centralization of information technology services at a large public university. Annals of Cases on Information Technology, 5, 201-213. Retrieved October 20, 2006, from ProQuest database.

6. Orlikowski, W.J. and Gash, D.C. (1994). Technological frames: Making sense of information technology in organizations. ACM Transactions on Information Systems, 12 (2), 174-207.

7. Olsen, F. (2001). Chapel Hill seeks best role for students' laptops requirement: Yields savings, but educational gains are evolving and hard to measure. The Chronicle of Higher Education, 48(4), A31. Retrieved November 19, 2006, from InfoTrac OneFile database.

8. Randall, C. (2001). Requiring students to bring computers to campus: Are universities achieving their goals? Proceedings of the International Academy for Information Management Annual Conference: International Conference on Informatics Education \& Research, New Orleans, LA, December 14-16, 141 145.

9. Tiu, F., Guglielmi, J. and Walton, W. (2002). Assessing a technology initiative: Lessons learned while integrating technology into teaching and learning. Paper presented at the Annual International Forum of the Association for Institutional Research, Toronto, Canada, June 2-5, 2002.

10. Wilgoren, J. (26 March, 2000). Invasion of laptops spurs a revolution in college teaching. The New York Times, A1.

11. Young, J. (1997). Invasion of the laptops: More colleges adopt mandatory computing programs. The Chronicle of Higher Education, 44(15), A33-A35. Retrieved February 13, 2001, from http://chronicle.com. 